\title{
THE ETHICS OF CLOUD COMPUTING: A REVIEW
}

\author{
Anuska Sharma \\ SOEIT, Sanskriti University, Mathura, Uttar Pradesh, India
}

\begin{tabular}{|c|c|c|c|}
\hline Journal & \multicolumn{3}{|c|}{$\begin{array}{l}\text { Samvakti Journal of Research in Information Technology } \\
\text { https://www.sjrit.samvaktijournals.com } \\
\text { Volume } 2 \text { Year of Volume } 2021 \text { Page No : } 57 \text { - } 64\end{array}$} \\
\hline Discipline & \multicolumn{3}{|l|}{ Cloud Computing } \\
\hline Conference & \multicolumn{3}{|c|}{$\begin{array}{l}\text { A virtual international conference on redefining and transforming the role of higher } \\
\text { education in sustainable development }\end{array}$} \\
\hline Conference & \multicolumn{3}{|c|}{ Start Date: September 30, 2021} \\
\hline Dates & \multicolumn{3}{|c|}{ End Date : September 30, 2021} \\
\hline Institute Name & \multicolumn{3}{|c|}{$\begin{array}{l}\text { JAIN (Deemed-to-be University) in association with Council for Industrial } \\
\text { Innovation and Research }\end{array}$} \\
\hline $\begin{array}{l}\text { Date Received } \\
\text { ID } \\
\text { Dol }\end{array}$ & $\begin{array}{l}: \text { November } 19,2021 \\
: \text { 2021.02.17 } \\
: \text { 10.46402/2021.02.17 }\end{array}$ & $\begin{array}{l}\text { Publication Date } \\
\text { Paper Type } \\
\text { Dol URL }\end{array}$ & $\begin{array}{l}\text { : December 11, } 2021 \\
\text { : Conference Paper } \\
\text { : https://dx.doi.org/10.46402/2021.02.17 }\end{array}$ \\
\hline \multicolumn{4}{|c|}{$\begin{array}{l}\text { Access Type : Open Access (Attribution-NonCommercial-NoDerivatives } 4.0 \text { International) } \\
\text { (c) } 2021 \text { Anuska Sharma with publication rights granted to Samvakti Journals }\end{array}$} \\
\hline
\end{tabular}

\section{ABSTRACT}

Virtualization is increasingly increasing traction in the business sector. By delivering on-demand digital access, it allows companies save the expenditure on equipment and IT upkeep. It is the initial research in the realm of business morality to look at this new technologies. It investigates the administrative duties of webhosting companies that operate and administer virtualized datacenters (such as Amazon). It considers cloud services that rent 'cloud space' from shared server (e.g., Dropbox, Salesforce). It also investigates how companies and people utilize these solutions. The original article initial part contends that server companies, wireless carriers, and virtual servers all have bilateral information (epistemic) duties to share and seek answers on matters including user privacy, business reliability, information retrieval, and authorization. The cognitive quality of Interlucency is offered as a guiding principle for ethically effective communications. The second section looks at possible government restrictions or prohibitions on the development and usage of cloud computing technologies. Applying the concept of technical openness, it claims that interference with hosting companies and online resources is only ever required or permissible. Nevertheless, it is also alleged that businesses that employ cloud services (such as banking, legal firms, healthcare, and some other businesses that keep consumer files in the database) would be susceptible to stricter regulations. 
KEYWORDS: Cloud, Communication, Computing, Service, Software.

\section{INTRODUCTION}

Internet technology is being used by both companies and consumers to analyze, share, and integrate information, recruit persons, administer support for consumers and advertising, and an increasing number of other functions. Internet vendors that collect and manage information in massive datacenters are progressively providing computational power as on-demand solutions. Virtualization, a new Systems Integration (IT) architecture, offers major advantages in respect of deployment, configuration, upgrading, adaptability, pricing, and computational power, and now it has benefitted a large amount of consumers in current history. It does, however, come with a number of possible drawbacks. In 2010, for example, there was a massive cyber assault on Gmail, a major cloud email provider, and Amazon abruptly stopped providing cloud services to Wikileaks. Following the NSA espionage incident in 2013, the iCloud nude image leak in 2014, and the Sony assault, cybercriminals progressively turned to the clouds. It was the initial research on virtualization in the realm of business morality ${ }^{[1][2][3]}$.

It takes a data-driven or epistemic ethical approach. The author address two problems after a short introduction of cloud computing technology and a survey of key parties.

First, we will talk about the educational pressure on clouders, which refers to efforts to educate and/or enlighten people and businesses that utilize cloud-computing services. Cloud computing, we notice, fits the interests and values of people who have a bloated perspective of freedom and a deflated view of ownership worth. This is especially true for Generation X and Millennial, which care little about where a photograph is stored but who really controls it. They are now more focused on possessing the power to do anything with that and the freedom to do so. They was called Generation Cloud in a research conducted by Goldsmith College professors and supported by Rackspace, a large hosted company. They're likewise consistent with the tendency it towards an loT technology wherein assets are transferred "from the commodity to the capabilities the commodity represents," i.e., an Everything-as-a-Service prospect wherein the users will not have to buy who own a textbook, just a permission to consume it on your EBook or even other device ${ }^{[4][5]}$.

In the commercial world, virtualization is fast acquiring acceptance. It lets businesses can save expense on infrastructure and IT maintenance by providing on-demand internet connections. This is the first study to looking at this breakthrough technique in the field of corporate morality. It looks at the informative responsibilities of sponsoring businesses that run and manage virtualized data centre (such as Amazon). Interlucency is portrayed as an intellectual virtue that may be used as a founding force for morally successful interaction. The second section examines possible political restrictions or prohibitions on the production and usage of cloud computing technologies. It asserts that interfering with server businesses and cloud resources 
was hardly necessary or acceptable, based on the notion of technological independence. Organizations that use online solutions, such as bankers, law offices, schools, and other businesses that store customer information in the web, are claimed to be susceptible to more stringent rules. In the current meaning, are better. It is currently employed in over 20 different ways, and it is regarded with scepticism by generally pro organizations as well as advertising agencies. It does, nevertheless, have a common denominator, which we'll define in layman's terms above ${ }^{[6][7]}$.

We use technology that is downloaded on such machines, the computers' CPUs to run the programme, and the quad core processors' hard disks to store copies of the documents. We could, though, have done it utilizing Google Docs' virtual suite. We might well have executed the application using software running on machines in Google's cloud data hubs from across world; we would have operated the application using Google's microprocessor and services; and we could all used only the systems to hold single document unless we had doing so. On the computer, we might well have collaborated. Although the approach we used to create the dissertation necessitated us to send photocopies of it back and forth though the mails, Google Sheets might well have allowed us to 'share' the manuscript and concentrate on it in the clouds at around the appropriate moment.

Cloud storage does often ensure that business collaboration easier for people. It also eliminates a requirement for the businesses to engage in cheap machines, information storage, regular maintenance, maintenance services employees, and a range of other items. All you get is a fundamental machine with Web internet, some simple programs like a free browsing, and a pay-per-use membership to the products you require. The computers in the data centres may, of obviously, fail. To limit the risk of business disruption due to electrical outages, datacentres are located near power generation, and files are saved in a number of geographical locations - the more sensory places at which ones information is housed, greater you pays. Amazon, for instance, has datacenters in Oklahoma, Oregon etc. Which is also true for various types of enterprises. Nonetheless, everything may go badly. Cloud solutions may have problems, leading them towards becoming unreachable for a brief period of time. Many organizations that depend on digital technologies may experience downtime, which will affect their webpages, consumer support, and/or sales operations. Small start-up enterprises are often the worst hit: In order to limit risk, cloud vendors need users to pay the extra to process information in numerous data centre, but smaller firms may be less likely to successfully to finance this. Assurance companies have started to develop coverage to protect many of the hazards associated with electricity shortages and technical glitches, and are offering them towards both internet resource suppliers and customers, however it is unclear how very much income enterprises will reap from this movement. 
The notion of cloud applications is nothing novel. Its revenue model is reminiscent of the times before companies and universities rented waiting time on massive device systems.

\section{Stakeholders:}

The first stage in an instructional equitable solution to internet applications is to identify the individuals who would be touched by public technology. Shareholders are people or organizations who are impacted by the consequences of company activities on their objectives or obligations. Examples include shareholders, entrepreneurs, employees, employees, customers, providers, competitors, organizations, and the ecology. For starters, the ecosystem is a most disregarded constituency.

Datacenters need a lot of energy, and approximately half of it is used to cool the CPUs alone. According to a 2010 research by Pike Research, cloud-computing adoption may decrease energy usage by almost $40 \%$ when compared to a business-as-usual scenario. The biggest benefit, it was claimed, comes from outsourcing computing activities from inefficient local datacenters (or home and office PCs) to hosting firms' more efficient large datacenters. Cloud computing has environmental benefits as well, since data is stored and computational activities are performed by servers and processors on the cloud, reducing the need to invest in ever more powerful gear. Recent papers, however, warn against too optimistic and hasty scenarios.

Government, but in the opposite contrary, serve as both participants. To begin, legislatures must determine if new laws should be enacted in result of new technology. Authorities, is from the alternative hand, might serve as a web server, a public technology supplier, or a corporation clouder. The Government, for example, has established its own "private" clouds for corporate IT processes rather than experimenting with competitive cloud - based services. San Francisco has been a trailblazer in moving applications to the business, "open" cloud for just some seasons. In an attempt to trace a midway path around open - ended and close platforms, the UK administration has formed the 'G-Cloud model,' which really is a completely unregulated arena where another cloud based business and the governmental meet.

Following that, we'll look at cloud gaming investments and the industry as a whole. Despite exact figures are harder to find by, strategists at UBS think that Amazon Web Services, the company's cloud division, had grown from about $\$ 200$ million in 2010 to a staggering $\$ 2.1$ billion by the third quarter of 2015 . Some internet technology companies don't strive to enhance technology and instead focus on providing rudimentary file, memory, and backing solutions. The fourth category, public cloud suppliers, has likewise produced impressive outcomes.

\section{Proscriptive Pressure:}

Recognize the distinction we drew before among holding firms that own manage storage systems, operating system solution players who produce certain kinds of 
Software-as-a-Service and rent "cloud space" from shared hosted, and commercial clouders who use those cloud computers technology? We believe that modest descriptive and prescriptive influence may indeed be directed to hosted companies and public cloud services, but that absolutist influence on corporation cloud users may be more severe. This idea is supported by a fundamentally liberal view that connects freedom with technological advancement. It is based on the idea that, despite intellectual and technological advancements may have disadvantages, administrations will be unable to anticipate the unfavourable implications of exploration \& innovation and, as a result, ought to refrain from meddling even during planning phase. The argument isn't that developing plainly dangerous technologies should have been allowed; it doesn't apply to renewable energy, for illustration, since its risks are rather evident. However, the idea is that legislative bans are unnecessary in a situation where significant evidence of serious harmful consequences have yet to appear. In this light, relatively little descriptive and prescriptive force is required in the cloud processing industry. Of fact, this applies only to the early stages of products discovery, since undesirable consequences may arise along the way, prompting a rethinking of public action.

Additional reason in favour of this idea is that restriction may have a dampening effect. Government may force IT businesses along certain ways and even have negative overflow effects in all other sectors if they stay on the safe zone and produce services unless there was no doubt that they will be technically permitted. It would also stifle creative ideas. For example, a legislature may force the cloud technology industry to fulfil certain protection or reliability standards, or prohibit knowledge discovery or personalized targeted advertising, all in the name of safeguarding consumers.

Our assertion that hosted businesses and public cloud services may experience modest prospective criticism, whereas corporate cloud users might confront more strong demand, aligns with arguments for innovation regulations. Our military does not distinguish amid various types of technology. The advancement of engineering the principle of technical independence asserts that the purpose of regulation is to govern effects and instead of means, which is why corporation clouders are treated any separately from infrastructure companies and cloud server. The ethical concerns of certain professional clouders' conduct are especially worrisome, as we shall see shortly.

However, business internet regulations may freeze adoption, and some (non-ICT) organizations may choose without implementing cloud solutions that, if deployed, could yield in performance improvements, for fear of non-compliance. We do not think, nevertheless, that these risks will manifest.

Especially if they really do, this has a smaller influence on ICT development and a larger influence on effectiveness strategies in businesses that can exist absent cloud applications. Corporations that depend on cloud applications will bear the risks. 
This in no way absolves the internet technology industry of accountability. As we covered in the previous paragraph, the cloud technology firm also has a duty to connect with consumers in a simple and straightforward way. If the manufacturing and their own client base are available to do and settlement agreement even they believe is in their own mutual interest, after which purchasers must have comprehensive and satisfactory awareness of what they might be purchasing. As we've seen, this involves much than simply quite well individual licensing accords; it also involves the kind of genuine interfluent communications that we proposed in the earlier part.

While we support mild descriptive and prescriptive influence on hosting companies and public solutions, we predict that descriptive and prescriptive impact on businesses that use cloud computing, or commercial clouders, will be far more severe. Whereas the basic notion is that regulation must not stifle invention, normative coercion is unlikely to own this effect since corporation clouders' principal operations are not virtualization technology. To assist descriptive and prescriptive pressures on corporate clouders, we'll look at a number of cloud services features that might have a negative impact on various stakeholders as a result of their activities. In addition, the author will examine what kind of normative pressures may be employed as a reply.

To begin with, the security systems of virtualized influences the likelihood of servers, and hence data, being stolen. Despite the popularity of online crime, criminals have shown an understanding of the physiological servers, with several court cases indicating that information stored on these servers was used for unlawful purposes. However, as more organizations turn to cloud services, the risk of this kind of crime will decrease since criminals will have a harder difficulty identifying which machines in the datacenters have the information they need. Unlike a bank's computer, which has just one purpose and is an obvious target for burglars seeking for data on security numbers, account credentials, and the like, cloud gaming data centers include a variety of data, making burgling them less enticing. Because of their larger impact, physical terrorist attacks on cloud data centers were expected in the early days of cloud services. The usage, on the other hand, seems to be a more significant issue.

\section{DISCUSSION}

A rising percentage of individuals and businesses are turning to the web as their primary storage option. The advantages are numerous: no configuration, no maintaining, no rebuilding, no interoperability difficulties, low costs, and computational capability for other than their own PCs, workstations, and storage arrays. Many companies are engaged in this even when they have experienced a data expansion (known as Big Data) that their in-house computer systems can no long handle. Banks, medicinal industry, private insurers, brand management, consultancy services and scientific centers, and many others benefit greatly when the data storage company earns exceedingly complex desktop activities viable and inexpensive by combining innumerable microprocessor spread across the world. 


\section{CONCLUION}

The author has reached a conclusion on Cloud Based Principles. On the other side, virtualization has several disadvantages. To begin with, most cloud services are unfamiliar with the concept of cloud software. We made the argument that this is down to a shortage of open correspondence between both the public cloud sector in this country, and that in order to compete with decency in this new economies, planning to host industries and cloud server must do anything conceivable to make sure that consumers recognize what they would be buying. Secondly, we proposed that monitoring of server companies and public cloud services should be limited to a range level, since universally applicable influence might suffocate entrepreneurship. Oversight of cloud software suppliers' business customers, on the other hand, is crucial. In attempt to implement the most efficient use of storing space, server companies and cloud resources often move their consumers' data with one location towards others. 


\section{REFERENCES}

[1] I. A. T. Hashem, I. Yaqoob, N. B. Anuar, S. Mokhtar, A. Gani, and S. Ullah Khan, "The rise of 'big data' on cloud computing: Review and open research issues," Information Systems. 2015, doi: 10.1016/j.is.2014.07.006.

[2] V. Pushpalatha, K. B. Sudeepa, and H. N. Mahendra, "A survey on security issues in cloud computing," Int. J. Eng. Technol., 2018, doi: 10.23956/ijarcsse/sv7i5/0217.

[3] K. Akherfi, M. Gerndt, and H. Harroud, "Mobile cloud computing for computation offloading: Issues and challenges," Applied Computing and Informatics. 2018, doi: 10.1016/j.aci.2016.11.002.

[4] C. Stergiou, K. E. Psannis, B. G. Kim, and B. Gupta, "Secure integration of loT and Cloud Computing," Futur. Gener. Comput. Syst., 2018, doi: 10.1016/j.future.2016.11.031.

[5] B. de Bruin and L. Floridi, "The Ethics of Cloud Computing," Sci. Eng. Ethics, 2017, doi: 10.1007/s11948-016-9759-0.

[6] Q. Zhang, L. Cheng, and R. Boutaba, "Cloud computing: State-of-the-art and research challenges," J. Internet Serv. Appl., 2010, doi: 10.1007/s13174-0100007-6.

[7] S. Shilpashree, R. R. Patil, and C. Parvathi, "'Cloud computing an overview," Int. J. Eng. Technol., 2018, doi: 10.14419/ijet.v7i4.10904. 